\title{
Innovative Design of Belt Conveyor Support Roller Based on TRIZ
}

\author{
Qi-li WANG ${ }^{a^{*}}$, Yan LI ${ }^{\mathrm{b}}$
}

School of mechanical and electrical engineering Beijing Institute of Graphic Communication, Beijing

Key Laboratory of Digital Printing Equipment, Engineering and Research Center of Printing

Equipment of Beijing Universities, Beijing-China

a18801112065@163.com, bliyan_peng@bigc.edu.cn

${ }^{*}$ Corresponding author

Keywords: Belt conveyor; Roller; TRIZ theory; Innovative design.

Abstract. For now the belt conveyor roller has short service life, high rolling resistance, heavy weight, large noise problems, leading to the roller work effect is not ideal. This paper uses the TRIZ theory for innovative design of belt conveyor roller to simplify the inner structure of the roller, and reduce the rotation resistance of the roller, so as to solve the problem of low efficiency of the belt conveyor.

\section{Introduction}

Belt conveyor is the transport equipment of continuous operation, in heavy industrial departments of power, metallurgy, chemical industry, coal, mine, port, building materials and transportation department is mainly used to transport bulk goods, such as ore, coal, sand powder, block and packaged into pieces of goods [1]. Roller is the largest number of belt conveyor in the rotating parts, the roller bearing the entire belt conveyor by the resistance of more than $70 \%$. As shown in Figure 1, roller bearing conveyor belt and conveying the full weight of the conveyor belt, is caused by friction loss in most parts, and belt conveyor in the most prone to failure, damage, the most consumed, most noise sources. At present, there is short service life, large rotation resistance, weight, noise and other issues of roller. And the problem of the roller has a direct impact on the efficiency of the conveyor, so it is very important to solve the problem of the roller. In this paper, use TRIZ theory to carry on innovative design of belt conveyor.

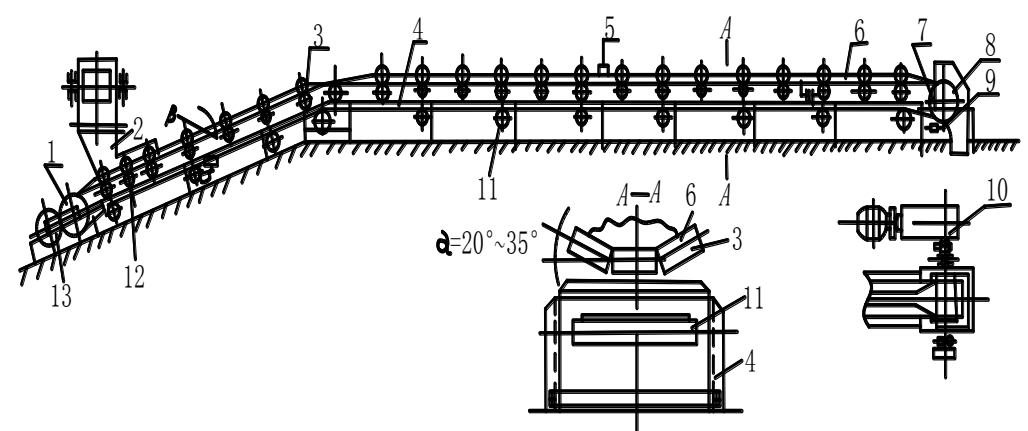

1. Tail (modified) roller; 2 .Feeding device; 3 .Upper support roller; 4. Frame;

5. Safety protection device; 6 .Conveyor belt; 7.Transmission drum; 8. Unloading device;

9. Cleaning device; 10. Driving device; 11.Lower supporting roller;

12. Buffering supporting roller; 13.Tension devic

Fig. 1. Schematic diagram of belt convey

\section{Problem Analysis}

Systems Analysis. The internal structure shown in Figure 2 for an existing high roller [3], including roller shaft, roller and outer roller, bearing block, labyrinth seal, end cover, elastic collar, active seal, active seal bearing, bearing, support plate and other components. The basic function of the roller is to support the conveyor belt, the auxiliary function is to adjust the flat conveyor belt. 


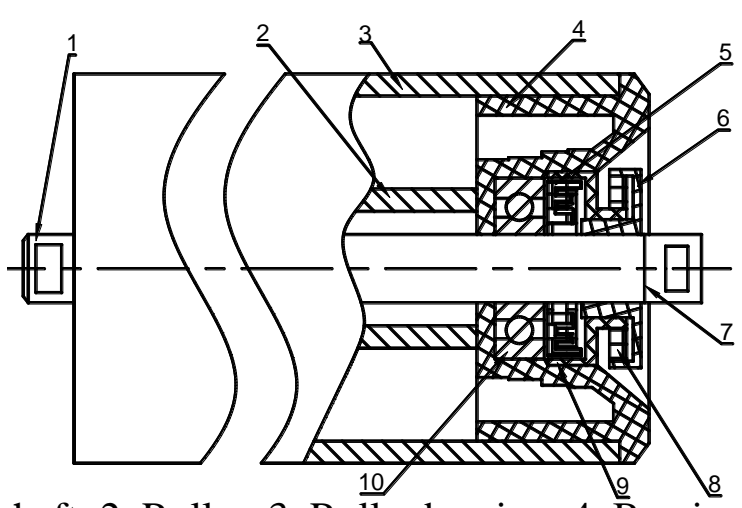

1. Roller shaft; 2 .Roller; 3. Roller bearing; 4 .Bearing block;

5 .Labyrinth seals; 6 .End cover; 7 .Elastic collar;

8. Active seal; 9. Active seal bearing;10. Bearing

Fig. 2 The internal structure of roller

Starting with the function of the system diagram, identifying the main function, system and the super system, the analysis of the components of the roller, as shown in Table 1.

Tab.1 Component analysis

\begin{tabular}{|l|l|}
\hline \multicolumn{1}{|c|}{ Technical system: roller } & \multicolumn{1}{c|}{ Function: support conveyor belt } \\
\hline \multicolumn{1}{|c|}{ System component } & \multicolumn{1}{|c|}{ Super system components } \\
\hline Roller & \\
Outer roller & \\
Bearing block & \\
Labyrinth seals & Conveyor belt \\
End cover & Frame \\
Elastic collar & Air (impurities) \\
Active seal & \\
Active sealing bearing & \\
Bearing & \\
Roller shaft & \\
Support plate & \\
\hline
\end{tabular}

And then analyze the relationship between the components of the component analysis table, as shown in Table 2.

Tab. 2 Component relationship analysis

\begin{tabular}{|c|c|c|c|c|c|c|c|c|c|c|c|c|c|c|}
\hline component & 1 & 2 & 3 & 4 & 5 & 6 & 7 & 8 & 9 & 10 & 11 & 12 & 13 & 14 \\
\hline 1 & & + & - & + & - & - & - & - & - & - & + & - & - & + \\
\hline 2 & + & & + & - & - & - & - & - & - & - & - & - & - & + \\
\hline 3 & - & + & & + & - & - & - & - & - & - & - & - & + & + \\
\hline 4 & + & - & + & & - & - & - & - & + & + & - & - & - & + \\
\hline 5 & - & - & - & - & & + & - & - & + & + & - & - & - & + \\
\hline 6 & - & - & - & - & + & & + & + & + & - & + & - & - & + \\
\hline 7 & - & - & - & - & - & + & & - & - & - & + & - & - & + \\
\hline 8 & - & - & - & - & - & + & - & & + & - & - & - & - & + \\
\hline 9 & - & - & - & + & + & + & - & + & & - & - & - & - & + \\
\hline 10 & - & - & - & + & + & - & - & - & - & & + & - & - & + \\
\hline 11 & - & - & - & - & + & + & + & - & - & + & & + & - & + \\
\hline 12 & - & - & - & - & - & - & - & - & - & - & + & & - & + \\
\hline 13 & - & - & + & - & - & - & - & - & - & - & - & - & & + \\
\hline 14 & + & + & + & + & + & + & + & + & + & + & + & + & + & \\
\hline
\end{tabular}

1. Roller; 2. Support plate; 3.Outer roller; 4.Bearing block; 5.Labyrinth seals; 6.End cover;

7. Elastic collar; 8.Active seal; 9.Active seal bearing; 10. Bearing; 11.Roller shaft;

12.Frame; 13. Conveyor belt; 14.Air 


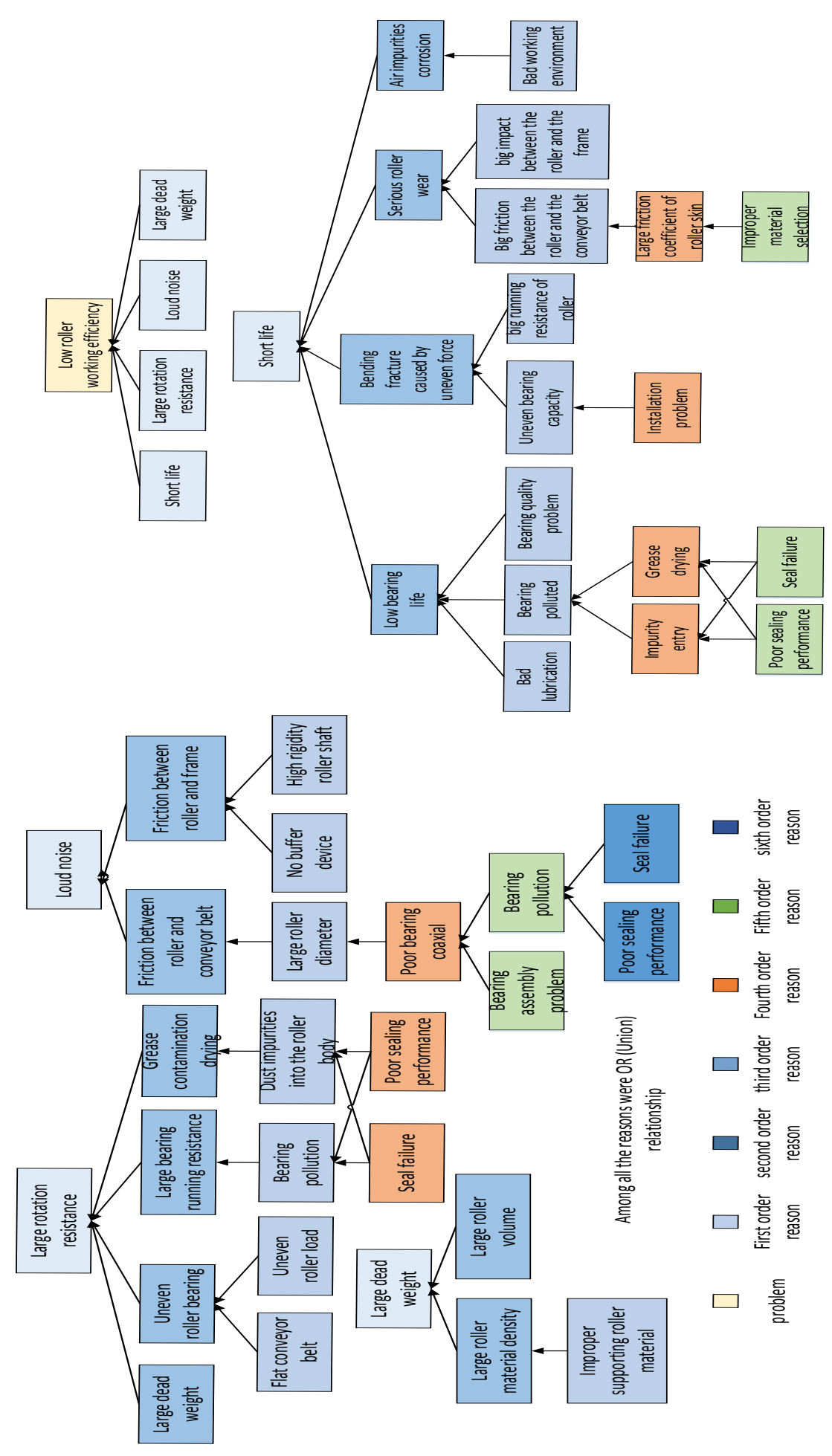

Fig. 3 Causal chain analysis

\section{Causal Chain Analysis}

The belt conveyor in the process of operation, there are major problems, conveyor belt off-tracking, conveyor belt slip, lower work efficiency, driving roller slipping, unbalanced power distribution, cleaning device failure. The main problem of this paper is that the work efficiency of the roller is caused by the running of the conveyor, that is, the problem of the efficiency of the conveyor.

Initial Defect Analysis. According to the solution to the problem in this paper, the initial disadvantage is that the efficiency of the roller is low. 
Middle Defect Analysis. The middle defect refers to the disadvantages and shortcomings between the initial end faults, it is consequence link both cause and consequence, and leads to the inefficiency of middle roller defect analysis as shown in Figure 3.

End Defect Analysis. Digging deeper will be irrelevant to the problem of the study, so the choice of the end of the shortcomings is the seal failure or inadequate.

Through the causal analysis, the establishment of the work efficiency of the roller chain of cause and effect as shown in Figure 3.

Do causal chain analysis of the existing problems of roller and find the cause of the problem layer by layer. From the above causal chain analysis, it can be known that the reason for the existing problems of roller are as follows.

Tab.3 Existing problems and cause of roller

\begin{tabular}{|c|c|}
\hline problem & cause \\
\hline $\begin{array}{l}\text { Large rotation } \\
\text { resistance }\end{array}$ & $\begin{array}{l}\text { The bad sealing effect of the roller is to cause the air impurities to enter } \\
\text { the roller body, pollute bearing, harden grease, and increase the rotary } \\
\text { resistance of the roller. }\end{array}$ \\
\hline Short service life & $\begin{array}{l}\text { Due to the large dead weight, in the process of the roller running, the } \\
\text { impact of the roller is larger, and the roller is easy to bend and break, and } \\
\text { the service life is shortened. }\end{array}$ \\
\hline $\begin{array}{l}\text { Large } \\
\text { weight }\end{array}$ & $\begin{array}{l}\text { The roller in the operation process, because of the seal is not good, } \\
\text { results the bearing pollution, reducing the service life of the roller. The } \\
\text { roller running environment is bad, will also affect the life of roller } \\
\text { conveyor belt, uneven wear will also reduce roller life. }\end{array}$ \\
\hline
\end{tabular}

To simplify the above problems, we can know that the core of the roller problems is: the roller is heavy, the rotation resistance in the process of operation is large, the seal is not poor and the ability to resist impact and limit bearing capacity are poor.

\section{Physical Contradiction and Design of Separation Principle}

Taking into account the complexity of the problem, and a large number of factors, this paper failed to solve the root cause of the engineering system. The core issue is: the large dead weight makes roller have large inertia in the operation process, suffering a large impact causes large rotation resistance, the roller will be bending and breaking, have big noise, shorten the life of roller; but small dead weight will lead to the weak impact roller capacity and ultimate bearing capacity. The two core issues are composed of a physical contradiction analysis as shown in Table 4.

Tab.4 Analysis of physical contradiction

\begin{tabular}{|l|l|}
\hline IF: Small dead weight & IF : Large dead weight \\
\hline THEN : small running resistance of roller & THEN : strong Bearing capacity of roller \\
\hline BUT: weak bearing capacity of roller & BUT: big running resistance of roller \\
\hline
\end{tabular}

Based on the separation principle to solve the physical contradiction, the general steps are as follows: Figure 4

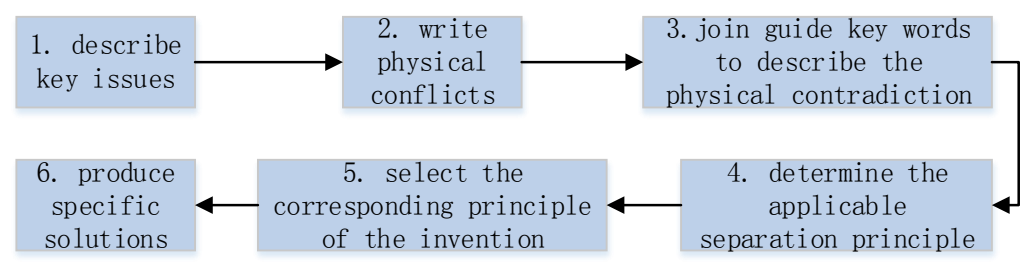

Fig.4 The steps to solve the physical contradiction based on the separation principle 
Through the separation of the principle of resolving the contradiction of the steps to determine the problem in this paper, the use of the principle of separation is space separation. There are six inventive principles based on spatial separation: invention principle 1: Division, invention principle 2: Extraction; invention principle 3: Local quality; invention principle 4: Non symmetric; invention principle 7: Nestification; invention principle 17: Spatial dimension variation. The principle adopted in this paper is No. 1 [4]. Though principle 1 the roller supporting plate is divided into a single support column, makes it discretization, and makes roller weight greatly reduced, not only improves the roller impact resistance and ultimate bearing capacity, and effectively reduce the roller revolving resistance at work, solve the problems .

The rotation of seal resistance is one of the main reasons, when the weight is reduced, the rotation resistance will be effectively reduced, and the corresponding seal for this reason has also been weakened. Thus, using Trimming to simplify the structure, realize innovative design. So you can get the final scheme of roller structure as shown in Figure 5.

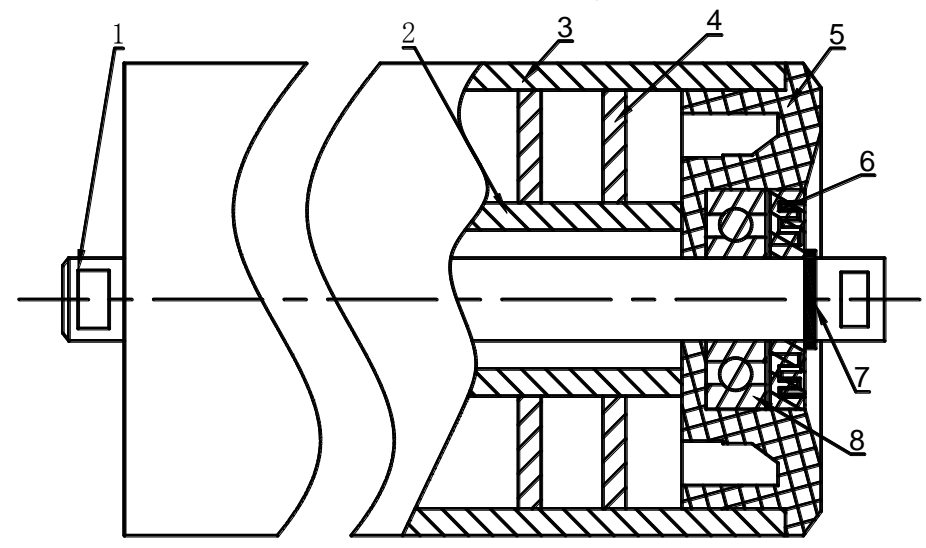

1. Roller shaft, 2. Roller, 3. Outer roller, 4. Support column, 5. Bearing seat, 6. Labyrinth seals, 7. Elastic collar, 8. Bearing.

Fig.5 The final program support roller internal structure

\section{Conclusion}

Roller problems affect the working efficiency of the conveyor directly. Through the TRIZ theory, carries on the innovation design to the belt conveyer support roller. The rotation resistance of the running process of the roller is reduced, solved the inefficient operation of belt conveyor in the process of problem successfully.

\section{Reference}

[1] Huang fei, Hou You-fu. "Design of test bench for supporting roller resistance of belt conveyor". Journal of Coal Mining Machinery . (2008).

[2] Cai Dong-dong. "Improvement of belt conveyor". Journal of China new technology and new products. (2013)

[3] Long Ri-sheng, Hu Da-wei. Invention patent of High molecular support roller device. 201410447768.3. Patent.

[4] Sun Yong-wei, Sergei IkeVanke.2015. TRIZ- the golden key to open the door of the innovation (I). Science press. (2015).

[5] Zhao Min, Zhang Wu-cheng, Wang Guan-shu. TRIZ advanced method and practice of the road to simple. Machinery Industry Press. (2015).

[6] Liu Ning, Li Yan, Jin Lin, Geng Hao, Yan Ying-cai. "Patent evasion design based on function oriented search and function tailoring". (2015). 